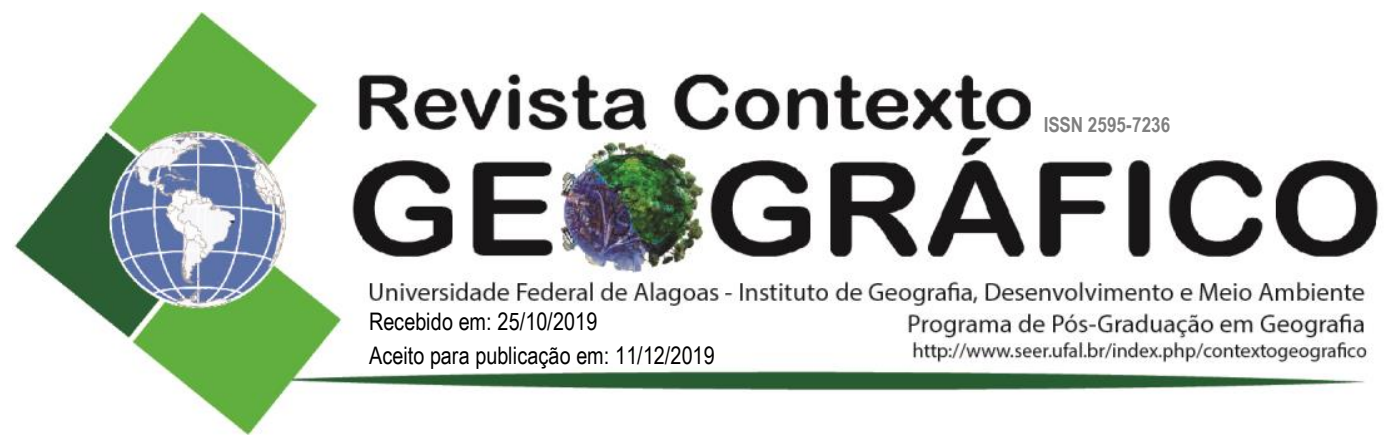

\title{
O CONTEXTO AMBIENTAL E POLÍTICO DA IMPLANTAÇÃO DO VEÍCULO LEVE SOBRE TRILHOS (VLT) NA CUIABÁ CIDADE VERDE: A RETIRADA DA VEGETAÇÃO DO TRECHO PARA O PROJETO DO VLT EM CUIABÁ, MATO GROSSO (2014)
}

\author{
Antonio Latorraca Netto \\ Pesquisador do Grupo Estudos Urbanos da Amazônia Setentrional (GEURBAS-UNIFAP), da \\ Universidade Federal de Mato Grosso, Mato Grosso, Brasil \\ antoniolatorraca@hotmail.com \\ José Carlos Ugeda Júnior \\ Professor Adjunto IV do Departamento de Geografia e do Programa de Pós Graduação em \\ Geografia, da Universidade Federal de Mato Grosso, Mato Grosso, Brasil \\ ugedajunior@gmail.com
}

\begin{abstract}
RESUMO - O objetivo geral do artigo foi analisar o processo de implantação do Veículo Leve sobre Trilhos (VLT), entre Cuiabá e Várzea Grande, no contexto da reestruturação da mobilidade urbana cujo foco, então, era atender exigências da Federação Internacional de Futebol (FIFA) para a realização da Copa do Mundo de 2014 na cidade, que serviu como subsede para jogos do mundial de futebol masculino. Dessa maneira, foram ao total: 107 obras de infraestrutura apontadas como necessárias para tal reestruturação, as quais, somente 48 obras foram finalizadas e 23 parcialmente concluídas. Afim de gerar condições físico-estruturais para as obras do trajeto dos dois eixos 1 e 2 do VLT e, para a implantação das estações terminais do modal, foram retiradas aproximadamente, 1.330 indivíduos arbóreos dos canteiros centrais das avenidas em que se projetava o referido modal. O presente artigo traz um acervo fotográfico acerca das alterações causadas antes e depois da retirada da vegetação e, assim, buscou realizar uma análise crítica sobre o desenvolvimento urbano com diretrizes ecológicas colocado em prática no contexto político do projeto ainda não concluído na cidade.
\end{abstract}

Palavras-chaves: VLT; Cuiabá; Impactos ambientais.

\section{ENVIRONMENTAL AND POLITICAL CONTEXT OF THE IMPLEMENTATION OF LIGHT RAIL VEHICLE (LRV) IN CUIABÁ “GREEN CITY": THE REMOVAL OF VEGETATION IN LRV PROJECT SITE IN CUIABÁ, MATO GROSSO (2014)}

\begin{abstract}
The general goal of this article was to analyse the implementation process of the Light Rail Vehicle (LRV) between Cuiabá and Várzea Grande, concerning the urban mobility restructuring, which focus at that time was to comply with the demands of the International Football Federation (FIFA) to hold the 2014 World Cup in the city, a host city for men's soccer matches. In total, there were 107 infrastructure works pointed as necessary for this restructuring, from which only 48 were finished and 23 were partially completed. In order to provide physical and structural conditions for the works of LRV lines 1 and 2 and for the implementation of the terminal stations, around 1,330 arboreal species were removed from the traffic islands of the avenues where the referred modal was being developed. This article provides a photographic collection about the changes caused before and after the removal of the vegetation and, thus, aimed to provide a critical analysis about the urban development with ecological guidelines put in place in the political context not yet finished in the city.
\end{abstract}

Keywords: LRV; Cuiabá; Environmental impacts. 


\section{PALAVRAS INICIAIS}

O presente artigo buscou abordar qualitativamente a temática ambiental e o contexto sociopolítico do ano de 2.014 na cidade de Cuiabá. De forma basilar esse estudo se desenvolveu, inicialmente, a partir de argumentos históricos e geográficos sobre a produção do espaço urbano de Cuiabá e do estado de Mato Grosso (SOUZA-HIGA, 2017; SIQUEIRA, 2017), a fim de compreender as artimanhas que a reprodução do espaço se revelou no contexto da reestruturação da mobilidade urbana em Cuiabá (Mato Grosso), reestruturação esta, tão somente à época, destinada a atender exigências para realização da Copa do Mundo de 2.014, no Brasil. Megaevento esportivo que teve Cuiabá selecionada como uma das cidades/subsedes de jogos do torneio mundial masculino.

O processo de implantação do Veículo Leve sobre Trilhos (VLT) na conurbação: Cuiabá e Várzea Grande1 foi analisado no artigo, no qual buscou-se enfocar os contextos das dualidades presentes de ações políticas e das diretrizes ambientais que animaram as dinâmicas espaciais na reestruturação da mobilidade urbana, impulsionada pelo projeto de implantação do VLT na cidade. Foram ao total: 107 obras de infraestrutura apontadas como necessárias para tal reestruturação, quando se acreditavam que elas facilitariam o deslocamento de pessoas e, com isso, haveria melhorias das relações sociais e econômicas na cidade, especificamente nos dias dos jogos do mundial em Cuiabá.

Entretanto, somente 48 obras foram finalizadas e 23 foram parcialmente concluídas. O VLT integra a lista de obras que nem sequer foram entregues à população usuária do transporte público. Anos depois dos jogos da Copa do Mundo de 2014, o espaço anteriormente ocupado por trabalhadores e por máquinas nos canteiros das obras do VLT, permanecem vazios - necessitando-se de regeneração - o que por si só, denuncia a problemática que se refere a não conclusão dessa que foi uma das obras mais caras para a Copa do Mundo, no Brasil, o que rendeu uma grande dívida pública sem legado para a população.

Nada obstante, no sentido de gerar condições físico-estruturais para o trajeto dos trilhos do VLT e, para a instalação das estações terminais, foram retiradas aproximadamente: 1.330 indivíduos arbóreos dos canteiros centrais das avenidas em que se projetava o referido modal (LATORRACA NETTO, 2013, 2016). Desse modo, o objetivo geral do artigo foi analisar o contexto ambiental e político dessa grande intervenção na infraestrutura da cidade de Cuiabá, e, o objetivo específico: analisar qualitativamente as áreas diretamente afetadas (ADA) e as áreas de influência direta (AID) das obras de implantação do Veículo Leve sobre Trilhos, projeto que passa exclusivamente por algumas das principais avenidas da cidade de Cuiabá e Várzea Grande.

As duas variáveis ambientais adotadas para análise, foram: a cobertura vegetal e a densidade populacional dentro da AID do projeto de implantação do VLT, que equivale a uma área de mil metros a partir dos eixos do VLT, como destaca a Figura 1 em hachura e o recorte temporal definido entre os anos $2.011-2.015$.

Figura 1. Área de Estudo: Área de Influência Direta (AID) do VLT Eixo 1 e 2 em Cuiabá 


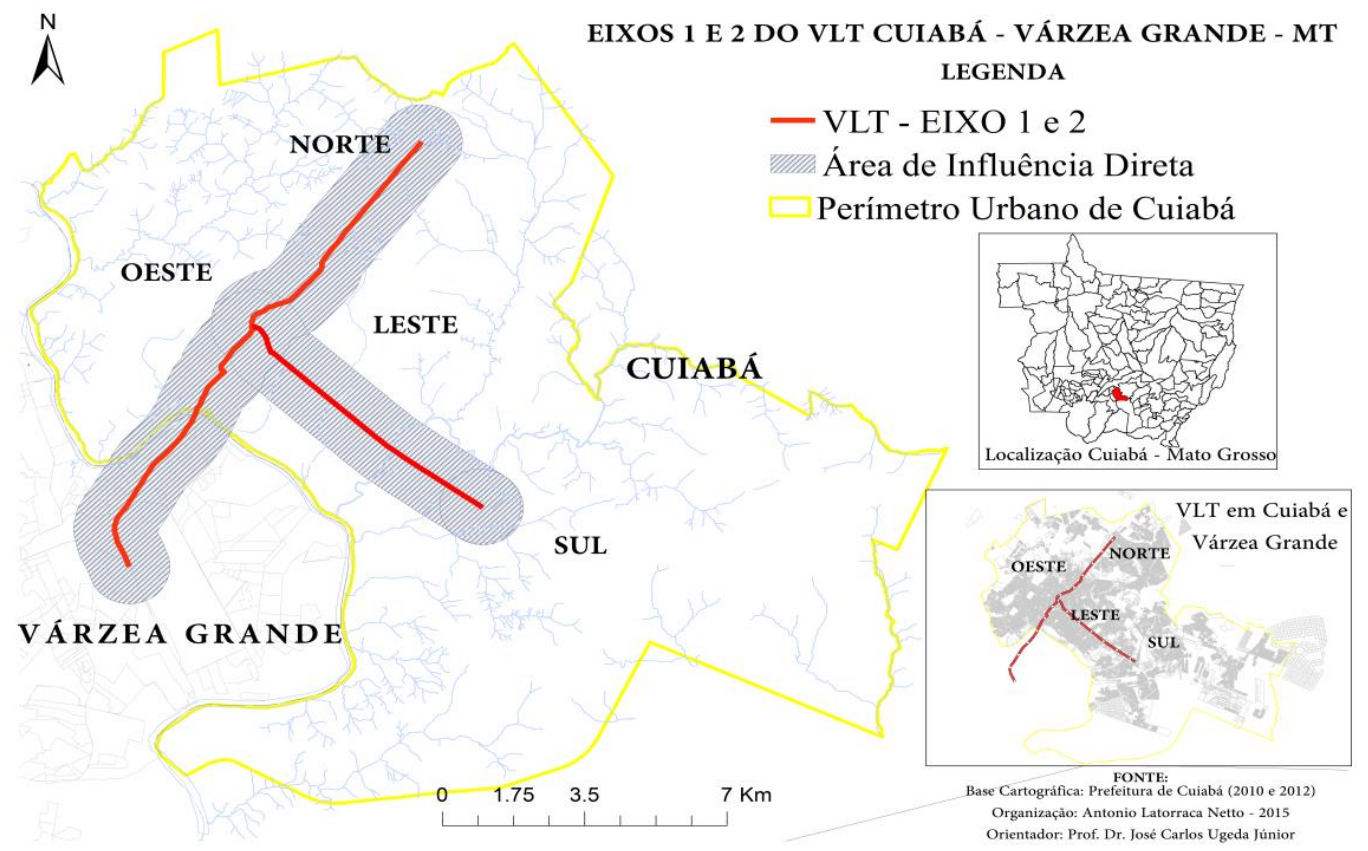

Fonte: SEPLAG-MT, 2011. Organização dos autores, 2018

\section{MATERIAIS E MÉTODOS}

O presente artigo percorreu três (III) etapas que se entrecruzam, foram: a primeira etapa (I) pesquisa bibliográfica, documental e referencial, que teve como foco o embasamento teórico e conceitual; (II) pesquisa de campo e laboratório, onde lançou-se mão de observação direta intensiva, construção do acervo fotográfico da pesquisa e, por meio dessa, enfocamos os atributos geoambientais e urbanos para subsidiar à análise sobre as alterações ocorridas entre 2011 e 2015, principalmente no que se refere à vegetação; (III) conclusão do estudo.

A sistematização de um banco de dados visando apresentar o sítio urbano da cidade de Cuiabá por onde percorreria o VLT (ADA e AID), foram de absoluta importância, bem como, o uso das imagens de satélite oferecidas pelo programa do website Google Earth (CNES2), que foram analisadas de maneira estratégica para caracterização e comparação, considerando um recorte temporal entre os anos $2.011-2.015$.

Pela realização pesquisas de campo, foi possível o registro e a organização das informações da área de estudo, quando foram: a) adquiridos dados fotográficos (imagens); b) anotações e observações sobre os principais componentes da paisagem no decorrer do traçado, especificando as áreas em que se observavam maior susceptibilidade para o agravamento de impactos ambientais negativos com relação à retirada da vegetação.

O Sistema de Informação Geográfica QGIS 3.6.0 (Quantum GIS), multiplataforma com códigofonte aberto, foi utilizado como instrumento computacional técnico e tecnológico que viabilizou o tratamento e a exposição dos dados e informações de caráter espacializável, tais como: os elementos que compuseram a análise da qualidade ambiental urbana e os dados cartográficos secundários que permitiam observar a localização da área de estudo em uma escala local e regional. 


\section{CARACTERIZAÇÃO DA CIDADE DE CUIABÁ/MT: A CIDADE VERDE?}

A fundação oficial de Cuiabá, então Arraial do Senhor Bom Jesus de Cuiabá, em 1.719 e, em 1.727 a fundação do município, constituindo sua extensão territorial de $3.538,17 \mathrm{~km}^{2}$, foi muito influenciada pela exploração de ouro de aluvião, por meio de garimpos às margens do rio Coxipó e do rio Mutuca, na localidade do Arraial da Forquilha, e, da histórica descoberta de jazidas de ouro, em 1718, às margens do Córrego da Prainha, nas Lavras do Sutil, imediações que compreendem o atual centro histórico da capital.

Tais descobertas, naquele tempo, atraíram migrantes de algumas regiões da colônia para Mato Grosso, no século XVII, fazendo com que inclusive, segundo o historiador Fausto (2013), a densidade populacional crescesse abruptamente, em função da presença dos trabalhadores escravos e pela vinda da sociedade de mineradores interessados nas riquezas e no poder que a extração aurífera já significava naquele tempo. A tabela 1 apresenta o aumento demográfico, especialmente, entre meados do século XIX e XX.

Tabela 1. Crescimento da População de Cuiabá nos anos: 1825; 1845; 1869; 1872; 1890; 1970; 1980; 1991; 2000; 2010; 2019 conforme Censos Demográficos do IBGE

\begin{tabular}{llllllllllll}
\hline ANO & $\mathbf{1 8 2 5}$ & $\mathbf{1 8 4 5}$ & $\mathbf{1 8 6 9}$ & $\mathbf{1 8 7 2}$ & $\mathbf{1 8 9 0}$ & $\mathbf{1 9 7 0}$ & $\mathbf{1 9 8 0}$ & $\mathbf{1 9 9 1}$ & $\mathbf{2 0 0 0}$ & $\mathbf{2 0 1 0}$ & $\mathbf{2 0 1 9} *$ \\
\hline POP. & 4.287 & 7.000 & 10.000 & 35.987 & 17.815 & 97.561 & 206.017 & 401.303 & 482.498 & 551.098 & 612.500 \\
\hline \multicolumn{8}{c}{ *Estimativa do IBGE para população 2019. Organização dos autores, 2019.}
\end{tabular}

E como demonstra a Tabela 1, a taxa de crescimento populacional entre os anos de 1.970 a 1.980 foi uma das mais altas, segundo os próprios cálculos do IBGE, girando em torno de 7,8\% de crescimento ao ano. Crescimento este, impulsionado pelas políticas de colonização e desenvolvimento empreendidas pelo Estado, apoiadas pelo governo civil - militar daquele período. A denominada abertura e expansão da fronteira pecuária, agrícola e mineral na Amazônia, foram os processos mais importantes que levaram à rede urbana do estado ser reestruturada em função dos altos fluxos migratórios e financeiros que trouxeram consigo a necessidade da implantação de novas cidades e/ou crescimento das que já existiam pelo estado (ROMANCINI, 2009, VILARINHO NETO, 2009, SOUZA-HIGA, 2017).

Atualmente, do ano de 2.000 à 2.010, a taxa de crescimento populacional anual (2000/2010) foi de $1,33 \%$ de crescimento ao ano, no qual o município de Cuiabá apresenta densidade demográfica de 155,83 habitantes por $\mathrm{km}^{2}$. No entanto, se em 2.010 a população total municipal chegou a 551.350 habitantes (IBGE, 2010), em 2.019 a estimativa do IBGE é para que atinja 612.500 habitantes, notando-se a relação entre o crescimento demográfico e, por conseguinte, o crescimento intra-urbano do aglomerado, tem sido caracterizado, sobretudo, pelo aumento dos espaços construídos.

Cuiabá situa-se na região Centro-oeste do Brasil, sendo a capital do estado de Mato Grosso, sua macrozona urbana de acordo o Perfil Sócio Econômico de Cuiabá (CUIABÁ, 2010) possui uma extensão de $254,57 \mathrm{Km}^{2}$, e encontra-se separada em regiões administrativas, a saber: regional sul $\left(\right.$ com 128,63 Km²); regional Oeste $\left(49,23 \mathrm{Km}^{2}\right)$; regional Leste $\left(46,01 \mathrm{Km}^{2}\right)$ e regional Norte $\left(30,70 \mathrm{Km}^{2}\right)$. Segundo o mapa de densidade demográfica por bairro (SMDU/DUP, 2010), o projeto do VLT perpassaria por meio de eixos por todas as regionais de Cuiabá e VG, notadamente por aquelas em que há maior destaque comercial e circulação de veículos, pessoas, bens e produtos.

O Rio Cuiabá é o principal curso de água da cidade percorrendo $18 \mathrm{~km}$ da área urbana, composto por vários afluentes: Rio Coxipó, Córrego da Prainha, Ribeirão da Ponte, Manuel 
Pinto (ou Córrego do Mané), Moinho, Barbado, Gambá, São Gonçalo são os cursos mais expressivos que integram a Bacia do Rio Cuiabá nesse perímetro, e muitos deles já apresentam degradação ambiental e poluição (GUARIM; VILANOVA, 2008, p. 17).

Nos dias atuais, Cuiabá, é considerada uma cidade de porte médio, sobretudo, considerada uma metrópole regional, pois, o estado forma uma área de polarização que se estende ao sul do Pará e parte do estado de Rondônia, como aponta os estudos de Vilarinho Neto (2009). Cuiabá, procurando seguir o modelo das estruturas das grandes cidades com o passar do tempo e por alterações na organização do espaço, vivenciou transformações da paisagem, onde teve seu verde (vegetação) desaparecendo, restando apenas algumas manchas verdes urbanas (MARTINS, 2005).

Embora seja uma cidade de porte médio, seus problemas ambientais são graves num contexto geral, pois Cuiabá vivencia problemas decorrentes de conflitos na interação entre o meio físico e do uso e ocupação do solo, principalmente problemas de saneamento básico e de conforto térmico.

A cidade, amplamente conhecida nos séculos passados, como a "Cidade Verde", segue passando por diversos processos que podem ser considerados como propulsores de uma reestruturação do aglomerado urbano e de seu entorno. Especificamente, o crescimento das intervenções urbanas para atender às exigências acordadas no Termo de Compromisso do Governo do Estado de Mato Grosso com a Federação Internacional de Futebol Associados (FIFA), visando à realização dos jogos mundiais da Copa do Mundo 2.014, contribuiu para que fossem implementados grandes projetos de obras civis no sistema viário do Aglomerado Urbano Cuiabá/Várzea Grande, como mostra a Figura 3.

Figura 3. Localização das grandes Obras Civis de engenharia no eixo 1 e 2 do VLT:

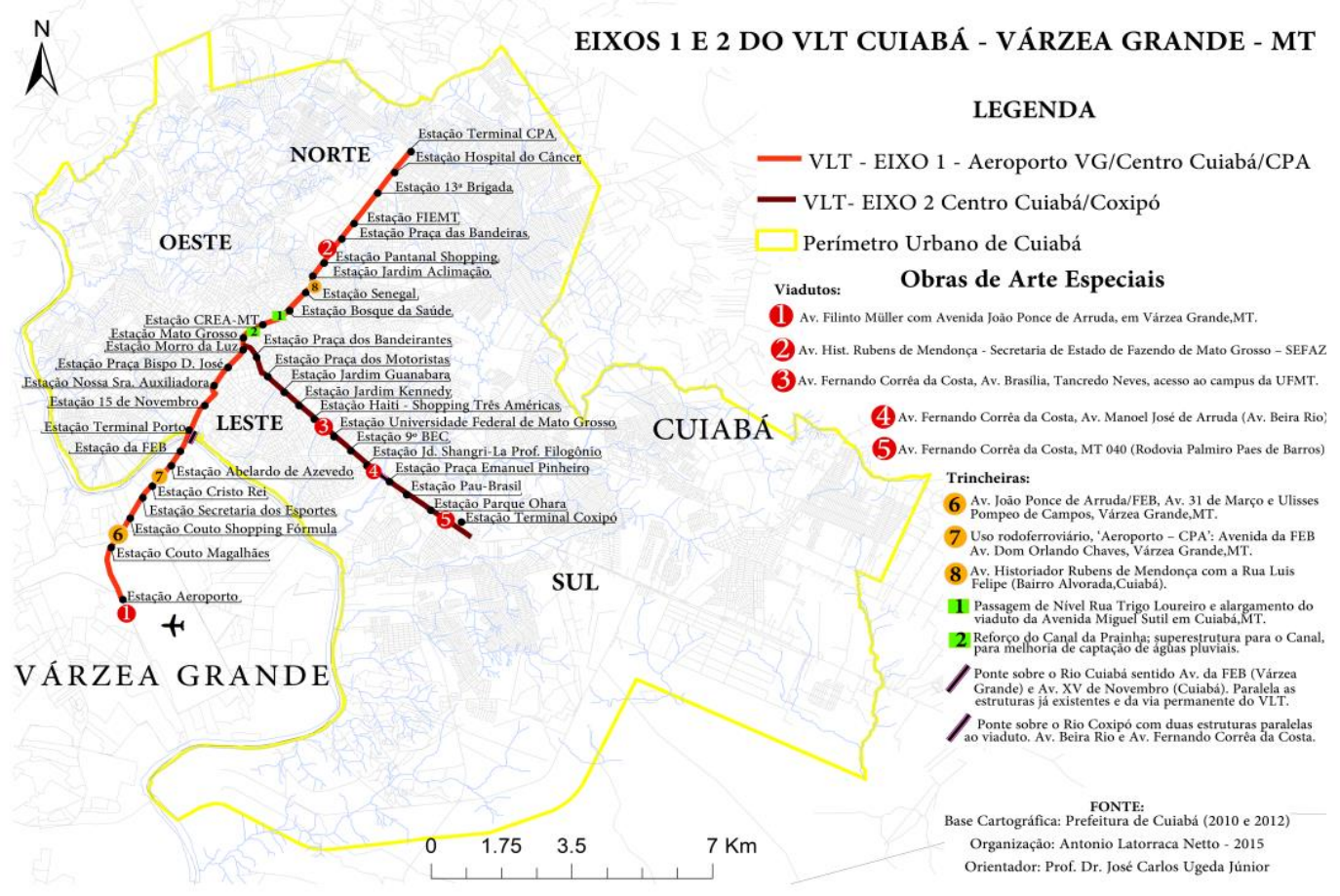

Fonte: Autores, 2016.

A Figura 3 evidencia somente as obras civis que incidiram sobre a área de estudo e que tiveram 
sua realização registrando alguns graves problemas, desde seu planejamento até a execução. Para muito além das incongruências políticas, por causa dos repasses em pagamentos de obras que sequer tinham sido entregues à população, alguns procedimentos de construção importantes que integram os eixos 1 e 2 no projeto do VLT, foram sendo executadas pelo Consórcio VLT Cuiabá/Várzea Grande sem a validação técnica de projetos de engenharia e arquitetura por parte do órgão estadual responsável ao monitoramento do andamento das obras. Possivelmente, esse fator foram um dos motivos que justificam o atraso na conclusão da infraestrutura, bem como, na qualidade questionável para obras dessa magnitude de investimentos.

As obras de mobilidade urbana foram projetadas em determinadas partes da cidade, onde tais transformações, no caso específico das obras de engenharia para viabilização da Copa do Mundo de 2014 na cidade, alteraram a paisagem urbana e serviram de apoio para difundir a expansão das atividades das incorporadoras e construtoras imobiliárias. Projetos imobiliários estes, localizados tanto nas áreas supervalorizadas pela especulação imobiliária quanto nas áreas de expansão urbana da cidade.

Não obstante, dependendo da localização dos projetos imobiliários, eles ocorrem em áreas com grande diversidade ecológica, tanto florística, faunística como hídrica e, isto representa na maioria das vezes em impactos negativos aos ecossistemas naturais e a sociedade como um todo. Como é comum na produção do espaço urbano que objetiva a reprodução ampliada de capital, esse crescimento urbano não se desenvolve planejado adequadamente, pois, não abrange a capacidade de suporte do meio, por que não há referenciais ecológicos que integram a estrutura e a dinâmica da paisagem aos modos de apropriação da natureza e do espaço concebidos nesses projetos.

\section{RESULTADOS E DISCUSSÃO}

\section{OBRAS DA COPA E IMPACTOS AMBIENTAIS URBANOS}

O torneio mundial de futebol masculino ou Copa do Mundo FIFA tornou-se um megaevento esportivo submetido aos interesses do capital. Pois para grandes empresas e corporações nacionais e multinacionais a sua realização significa o momento imprescindível para obtenção de altos lucros na comercialização de produtos, que vão desde objetos de uso pessoal até à espetacularização da paisagem urbana pela construção de uma imagem de cidade embelezada, porém, falsificada em conteúdos reais e amplos.

O megaevento esportivo é organizado pela FIFA e, ocorre a cada período de quatro anos, sempre em algum país anfitrião que se candidata para concorrer na seleção de futuras cidades-sedes de jogos. O tema principal da presente pesquisa dedica-se a entender o processo de urbanização, a partir da análise sobre o conjunto de obras que compõem o projeto de implantação do VLT em algumas das principais avenidas de Cuiabá e Várzea Grande.

Esse conjunto de grandes obras de infraestrutura, era um item fundamental para a reestruturação da mobilidade e a requalificação de Cuiabá para a Copa do Mundo, objetivava apresentar uma cidade cenário, apta à sediar jogos e atrativa para o desenvolvimento dos empreendimentos financeiros nacionais e internacionais, que integram o processo de realização de eventos dessa magnitude econômica, social e cultural.

Segundo Broudehoux (2014, p. 29), com a estetização da paisagem urbana, a visibilidade e a 'imaginabilidade' tornam-se critérios que passam a orientar as intervenções urbanas, onde com grande frequência é priorizada a imagem ideal em detrimento de necessidades locais fundamentais (BROUDEHOUX, 2014), tais como as demandas sociais por melhorias da saúde, do ambiente urbano, da educação e da cidadania de modo geral.

A mesma autora alerta que para as "massas empobrecidas da cidade" estas reconfigurações da 
estrutura urbana podem ser perigosas, visto que, os membros da elite local podem fazer desse processo a consolidação de uma cidade livre das classes inferiores socioeconomicamente, bem como, abrindo espaços assim para promoção de políticas urbanas exclusivas (BROUDEHOUX, 2014).

O projeto do VLT, foi um símbolo da modernização do transporte coletivo entre as duas maiores cidades da Região Metropolitana do Vale do Rio Cuiabá (RMVRC), consistiu em um vetor de renovação urbana que ocorreu por meio de um processo de reestruturação da cidade provenientes das transformações das formas de mobilidade e acessibilidade nas principais áreas de interesse econômico - financeiro da cidade.

E para a implantação dos corredores estruturantes desse transporte coletivo, o Anteprojeto do VLT (SECOPA-MT, 2011), afirmou a necessidade de redefinição e adequação das interseções ou rotatórias ao longo do projeto do traçado do modal e, ainda acrescentou a importância do desenvolvimento de viadutos e trincheiras nas interseções de maior complexidade (PARTE II, 2011a, p. 08).

Para tanto, o financiamento liberado pela Caixa Econômica Federal de R \$ 423 milhões, com pagamento em 88 meses (sete anos e quatro meses com juros), então aprovado para a implantação do Bus Rapid Transit (BRT) foi redirecionado para o projeto do VLT. Conquanto, somado a esse financiamento proveniente de recursos acordados com a Caixa Econômica Federal, houve mais outro, oriundo do Banco Nacional de Desenvolvimento Econômico e Social (BNDES), que se fez como o maior financiamento para o VLT, constituindo a ordem de aproximadamente R $\$ 727$ milhões, com a previsão de pagamento em um período de trinta anos com juros. O Governo do Estado de Mato Grosso realizou uma contrapartida não financeira de R\$ 110 milhões para completar os custos totais da obra, também recorrendo a mecanismos tributários de isenções fiscais.

Segundo o Consórcio VLT - Cuiabá e Várzea Grande (INAE, 2012, p. 01), o VLT contaria com: “(...) 33 estações para embarque e desembarque, 03 terminais de integração e operação, 01 pátio ferroviário de estacionamento e 40 veículos". A tabela 2 indica as principais características do modal, no que se refere a infraestrutura básica e quantidade de estações de embarque e desembarque previstas.

Tabela 2. Tabela 2. Estrutura básica do Veículo Leve sobre Trilhos - VLT.

\begin{tabular}{|c|}
\hline MODALIDADE \\
\hline $\begin{array}{c}\text { CORREDORES ESTRUTURAIS DE } \\
\text { TRANSPORTE COLETIVO }\end{array}$ \\
\hline LINHA 1 \\
\hline 15.035 metros (15 km) de extensão \\
\hline $\begin{array}{c}\text { Aeroporto Internacional em Várzea Grande - } \\
\text { Centro de Cuiabá -CPA }\end{array}$ \\
\hline LINHA 2 \\
\hline 7.145 metros (7 km) de extensão \\
\hline Coxipó - Centro de Cuiabá \\
\hline * Via Ferroviária Semi-Segregada. \\
\hline
\end{tabular}

\begin{tabular}{|c|}
\hline Veículo Leve sobre Trilhos* \\
\hline 33 Estações \\
\hline Embarque e Desembarque \\
\hline 03 Terminais \\
\hline Sistema Alimentador Rodoviário \\
\hline $\begin{array}{c}\text { 01 Complexo de Manutenção, } \\
\text { Administração } \\
\text { e Operação }\end{array}$ \\
\hline 01 Pátio Ferroviário de \\
Estacionamento \\
\hline 40 Veículos VLT \\
\hline
\end{tabular}

Fonte: Anteprojeto do VLT - SECOPA/ MT (2011). Organização dos autores, 2019

Em 2.013, associados ao processo de contratação da obra do VLT, sob o $n^{\circ}$ 001/2013/SECOPA- 
MT, foi contratado abril de 2.015 pela Secretaria Extraordinária da Copa do Mundo (SECOPA/MT), o Consórcio Planservi-Sondotécnica/ VLT Cuiabá e Várzea Grande pelo Regime Diferenciado de Contratação (RDC)3, para gerência e supervisão técnica da implantação das obras, (edital n ${ }^{\circ}$ 004/2012/SECOPA-MT), com custo total de R $\$ 46.988 .051,52$ (quarenta e seis milhões novecentos e oitenta e oito mil, cinquenta e um reais e cinquenta e dois centavos) com o prazo de execução e vigência de vinte e sete meses.

A obra mais cara para a Copa do Mundo 2.014, em Cuiabá, MT, segundo o site (lista10.org.br)4 foi o VLT. Com referência nos projetos desenvolvidos para atender às demandas exigidas pela FIFA para o mundial de futebol em 2.014, a obra do VLT promovida pelo estado de Mato Grosso foi a segunda mais cara no quadro de obras voltadas à mobilidade urbana no Brasil.

Mesmo em vista do altíssimo valor dos investimentos realizados em infraestrutura entre Cuiabá e Várzea Grande/MT visando à realização da Copa do Mundo 2.014 na cidade, as ações de reforma e reconstrução do estádio José Fragelli "Arena Multiuso Pantanal", a reforma e ampliação do Aeroporto Internacional Marechal Rondon em Várzea Grande; as obras de mobilidade urbana, especificamente, a implantação do VLT, entre muitas outras obras não ficaram prontas segundo o cronograma físico-financeiro do planejamento dos projetos básico e executivo, feitos por empresas contratadas pelo Governo do Estado de Mato Grosso entre os anos de 2.010-2.012.

A isso se devem inúmeras adaptações e improvisos estruturais que tiveram de ser feitos nos prazos que tais obras já deveriam ter sido entregues à população em 2.014. Os trilhos do VLT, foram parcialmente implantados no trecho do Eixo um na cidade de Várzea Grande como observa-se nas Figuras 5 e 6.

Figura 5. Eixo 1 VLT em Várzea Grande. Futura Estação do VLT - Secretaria dos Esportes sem conclusão.

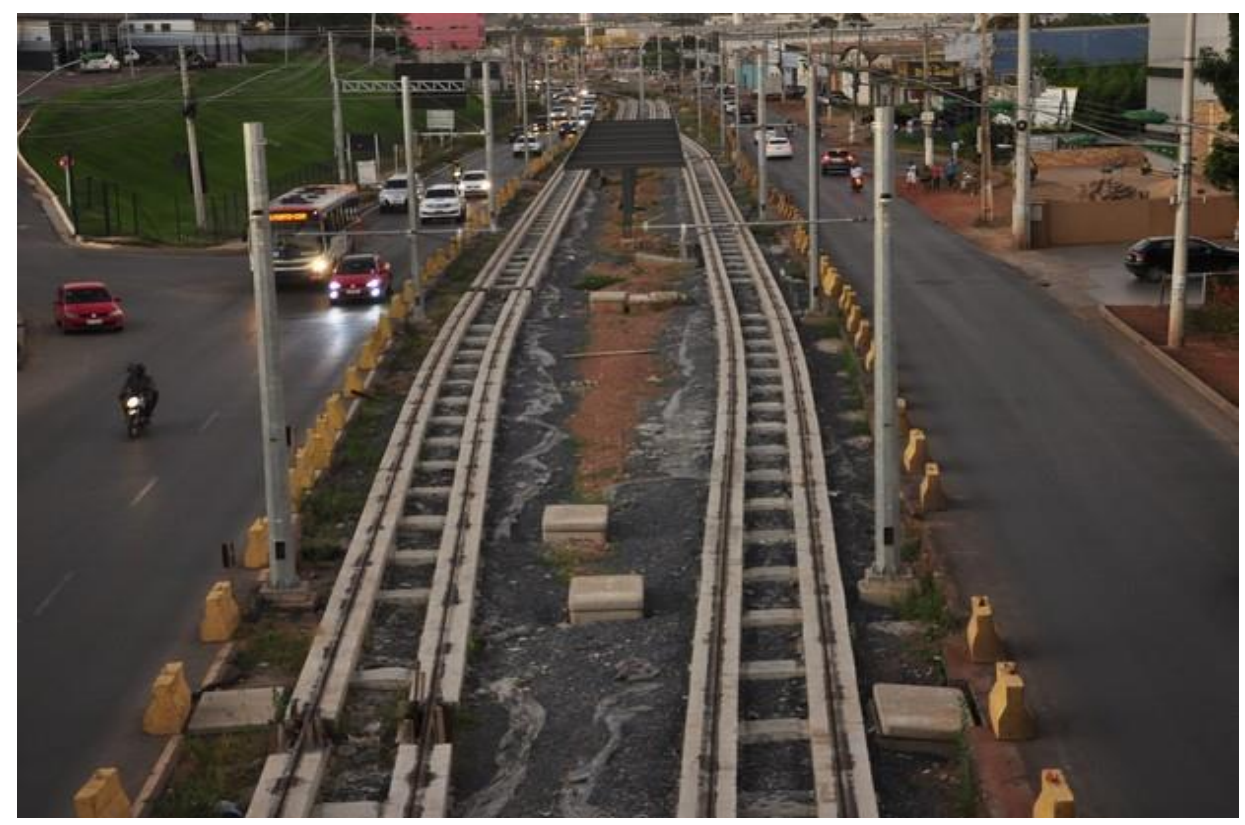

Fonte: <g1.globo.com.br> Reportagem do dia 20 de julho de 2015. Foto: André Souza - G1, 2015 
Figura 6. Eixo 1 VLT em Várzea Grande. Futura Estação Couto - Auto Shopping Fórmula, obra sem conclusão e paralisada.

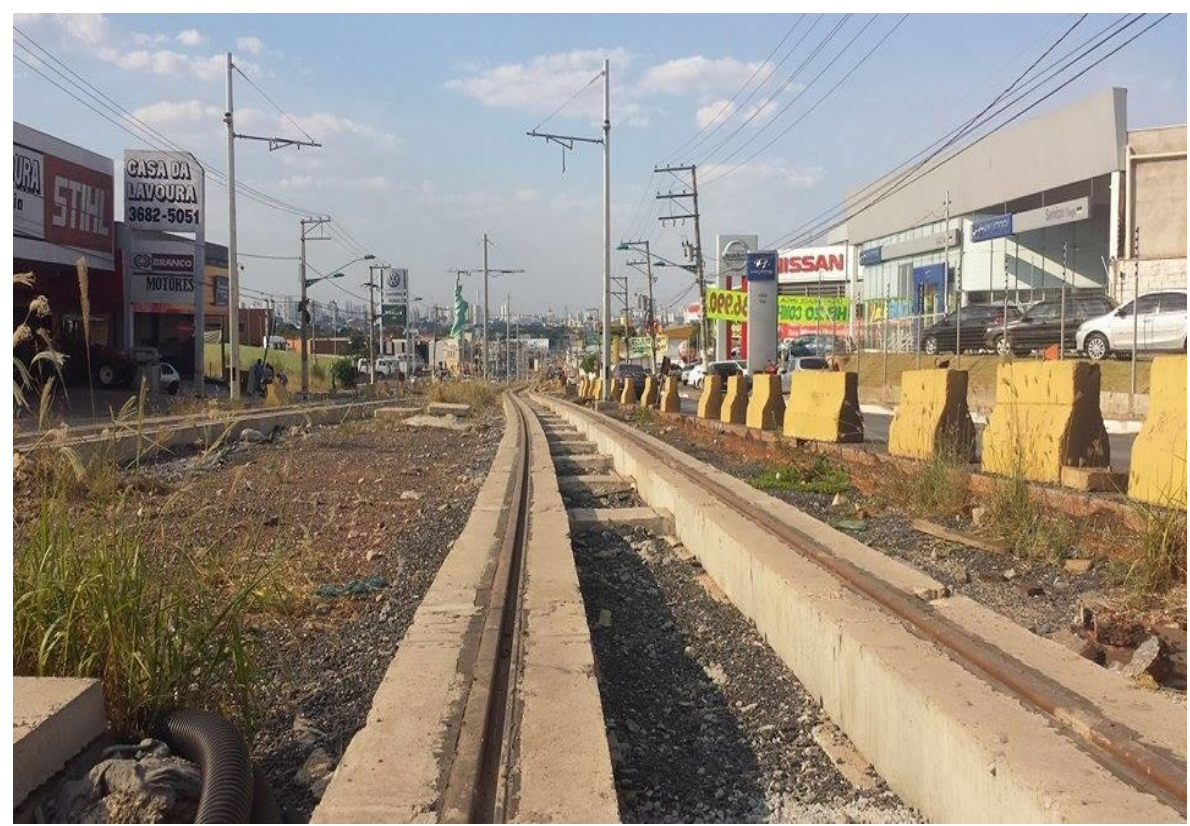

Foto: Latorraca Netto, 2015

A implantação do VLT envolveu o mais importante conjunto de obras de engenharia e arquitetura dos últimos anos na região, mesmo assim, não foi concluída para atender a demanda por transporte durante os jogos do mundial de futebol de $2.014 \mathrm{e}$, assim, permaneceu em estado de abandono pelo Governo do Estado e pela empresa contratada logo após a paralisação das obras do VLT, como demonstram as Figuras 7 e 8 do eixo um em Cuiabá/MT.

Figura 7. Eixo 1 VLT em Cuiabá. Avenida Hist. Rubens de Mendonça. Área da Estação do VLT Jardim Aclimação e da Trincheira Luiz Felipe sem conclusão e paralisada.

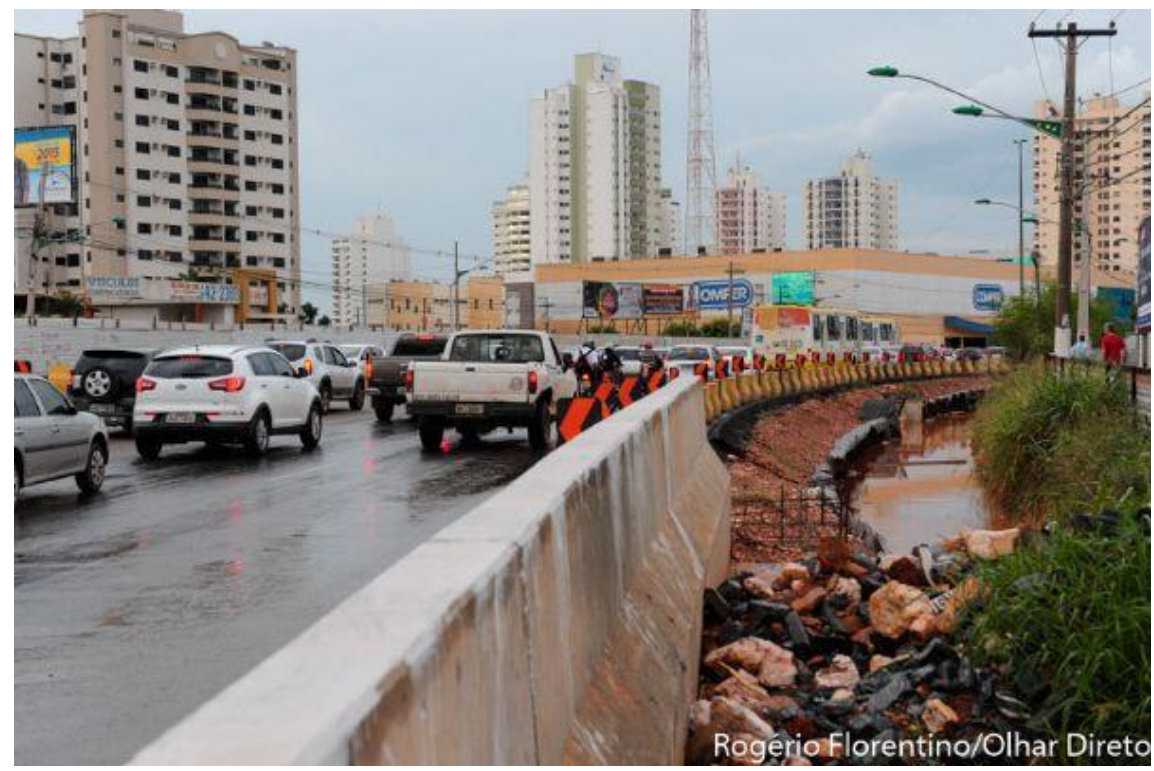

Foto: Jornal OD, 20145 
Figura 8. Eixo 1 VLT em Cuiabá. Avenida Hist. Rubens de Mendonça. Futuras Estações do VLT -Hospital do Câncer, da $13^{\text {a }}$ Brigada e da FIEMT sem conclusão e paralisada.

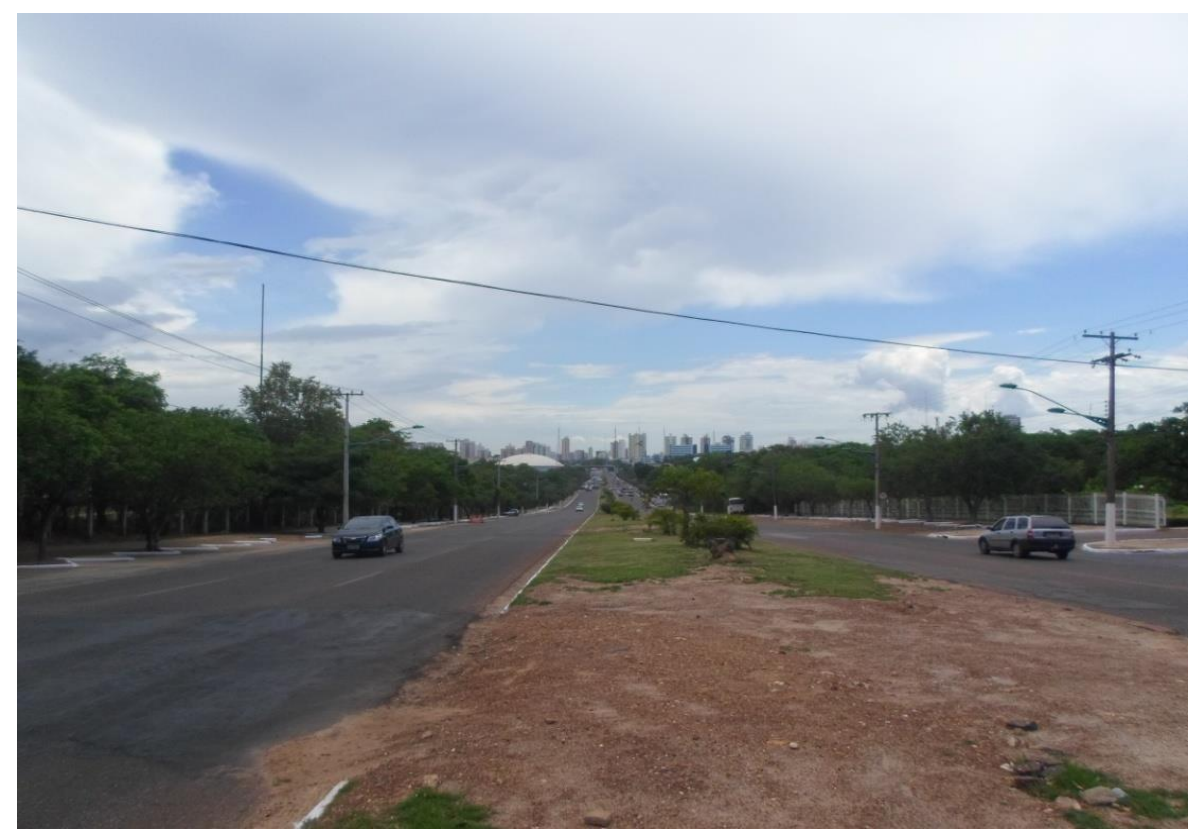

Foto: Latorraca Netto, 2014.

O Anteprojeto do VLT (SECOPA/MT, 2011) esteve ancorado em referenciais da Lei Complementar $n^{\circ}$ 150/2007 - Plano Diretor de Desenvolvimento Estratégico de Cuiabá; da Lei $\mathrm{n}^{\circ}$ 3.112/2007 que instituiu o Plano Diretor de Várzea Grande; da Lei Complementar n ${ }^{\circ} 231$ de 26 de Maio de 2011, que Disciplina o Uso, a Ocupação e a Urbanização do Solo no Município de Cuiabá; dentre diversas outras legislações municipais, estaduais e federais, como a Lei $\mathrm{n}^{\circ}$ 10.257/2000 - Estatuto da Cidade.

Segundo Secopa/MT (2011, p. 09), foram três projetos de engenharia elaborados como parte do escopo do projeto de contratação dos serviços, que deveriam fornecer elementos básicos de qualidade da obra e dos sistemas a serem implantados. O primeiro conjunto de projetos foi a elaboração do Projeto Básico de Engenharia, que planeja e autoriza o início de estudos ambientais e complementares. Estes estudos viabilizariam a obtenção de resultados positivos em processos administrativos que emitem as Licenças Ambientais. O Projeto Executivo de Engenharia viria em seguida, indicando e autorizando a execução das Obras Civis, fornecimento e implantação de sistemas de sinalização e controle, telecomunicações, energia e material rodante até à operação do sistema.

No Anteprojeto do VLT, existe a afirmação de que as condições específicas em todas as etapas desses projetos precisavam ser conduzidas por métodos e critérios reconhecidos, que seguiriam normas técnicas aplicadas na engenharia e na arquitetura. E ainda destacou que, a compatibilização de documentos técnicos no Projeto Básico precisava atender as exigências de órgãos externos, por exemplo, estudos de trânsito e drenagem urbana.

Em contraponto a orientação da SECOPA/MT, direcionadas ao consórcio que seria responsável pelas obras do VLT, as obras de arte especiais: Viaduto Aeroporto, Viaduto na Avenida Historiador Rubens de Mendonça (SEFAZ) denominado Jamil Boutros Nadaf; Viaduto UFMT (denominado Jornalista Clóvis Roberto), Viaduto Avenida Beira Rio, Viaduto MT 040, Ponte sobre rio Coxipó, Trincheira Avenida 31 de Março (Km Zero), Trincheira Avenida Dom Orlando Chaves (Cristo Rei), apresentaram problemas de projeto e de execução, segundo 
relatórios de vistorias técnicas da Controladoria Geral do Estado de MT (CGE/MT, n. ${ }^{\circ}$ 019/2015), que auditou especificamente os objetos de fiscalizações realizados pela empresa responsável na supervisão e gerência do VLT, o Consórcio PlanServi Sondotécnica.

Os referidos relatórios indicam que, a então consultoria contratada pelo Estado, notificou a SECOPA-MT por inúmeras vezes, no qual se alertavam sobre obras que estavam sendo executadas sem a realização e conclusão adequada de Projeto básico, Executivo e As Built, ou seja, a ausência de projetos para execução de grandes obras civis ao longo do traçado. Nas notificações feitas, algumas obras são citadas em destaque: o Viaduto da SEFAZ, a Trincheira Cristo Rei, e o Viaduto Aeroporto. Não obstante, os pagamentos feitos pelo Governo de Mato Grosso (2.011 e 2.012), eram adiantados sem a devida conclusão das obras feitas sem planejamento. O Relatório da Controladoria Geral também analisou a fiscalização com relação à qualidade das obras, e identificou problemas desde meras não conformidades técnicas até graves erros que comprometiam a edificação.

O Relatório do CGE/MT (n. ${ }^{\circ} 019 / 2015$ ) apontou ainda que 20\% dos problemas possuíam natureza grave: no Viaduto da Av. Fernando Correa (UFMT) no Eixo dois do projeto VLT, no Viaduto do Aeroporto, na Trincheira do Km Zero, na ponte sobre o Rio Cuiabá, no Viaduto da SEFAZ no Eixo um do projeto VLT, dentre outras obras.

O Viaduto da UFMT, nas áreas de influência do Eixo dois - sub-bacia do Córrego Barbado, dentre alguns problemas, a ausência de efetivo planejamento quanto à drenagem superficial e profunda do terreno resultou que em episódios de precipitação, a água e os materiais em suspensão na água encontraram dificuldades para escoar, causando alagamentos e enchentes, conforme observado na figura 9 no ano de 2.014 e na figura 10 no ano de 2.013 é possível visualizar antes da canalização e retificação total do trecho do Córrego Barbado, na ligação com a avenida Fernando Côrrea da Costa, entre, a UFMT, o Shopping Três Américas e a construção (2.013) do Viaduto UFMT (Clóvis Roberto).

Figura 9. Viaduto Da UFMT - Eixo 2 - Sub-bacia do Córrego Barbado problemas da drenagem urbana (obra prestes então a ser concluída).

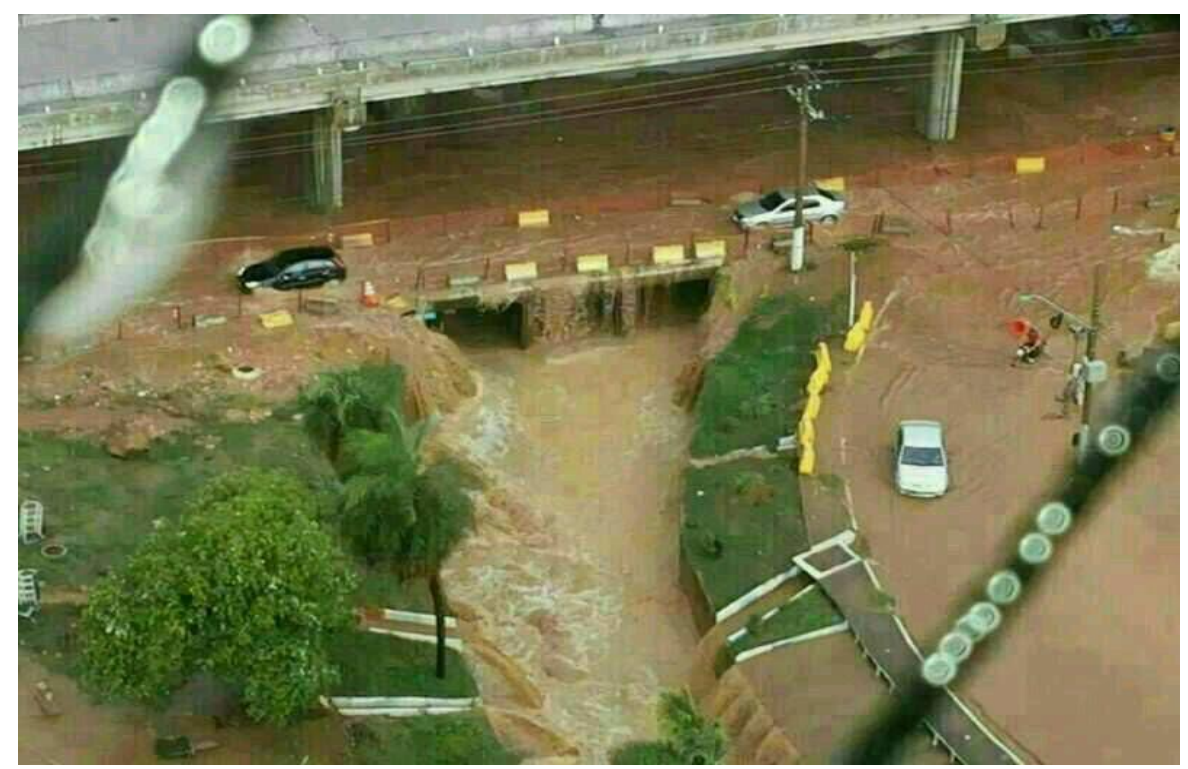

Fonte: Saragiotto, 2014 
Figura 10. Viaduto da UFMT - Eixo 2. Sub-bacia do Córrego Barbado antes das obras de canalização total do trecho

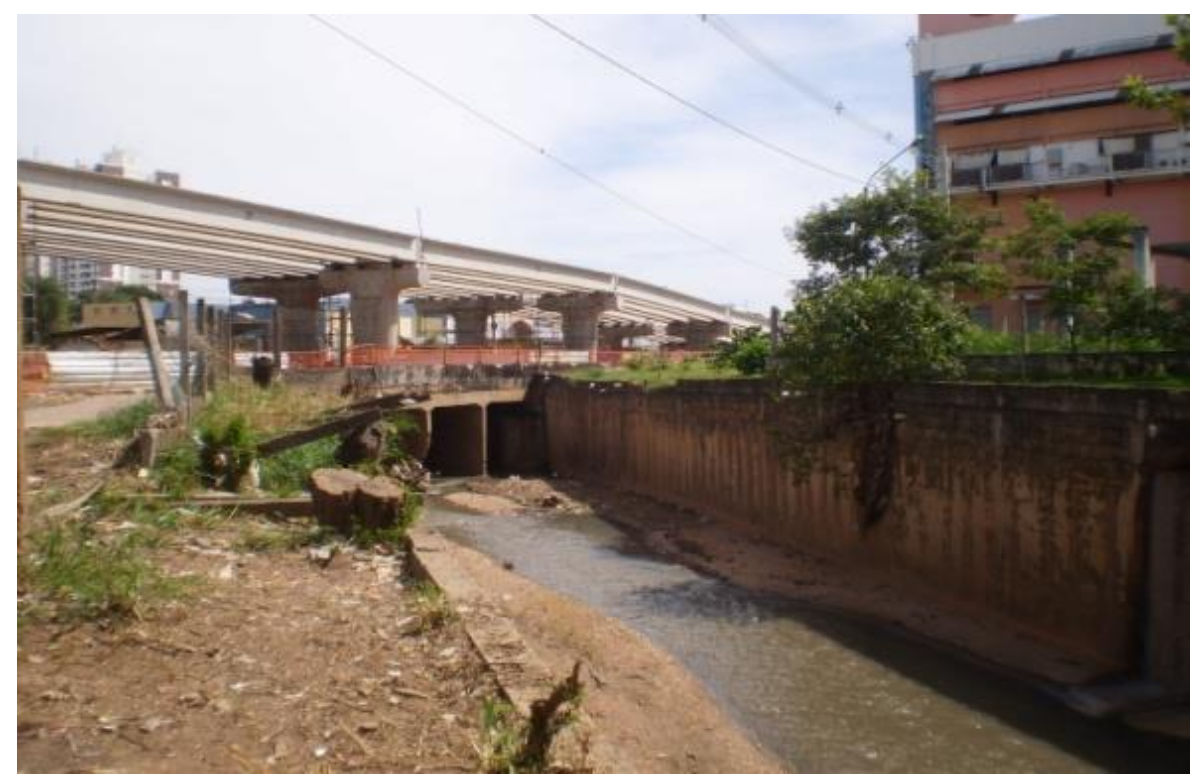

Foto: Latorraca Netto, 2013

O VLT estabeleceria a principal ligação de transporte coletivo e individual no sistema viário de Várzea Grande com Cuiabá, pelo Eixo 1: Em Várzea Grande o trajeto do VLT inicia pela avenida João Ponce de Arruda e Av. da FEB, correspondendo ao principal corredor de ligação Várzea Grande com área central de Cuiabá, a partir da conexão com a Ponte Júlio Muller no rio Cuiabá e com o deslocamento leste de Cuiabá com parte da regional norte de Várzea Grande têm-se o acesso ao Aeroporto Internacional Marechal Rondon e ao Centro de Várzea Grande. Tendo como principais interseções: Av. da FEB - Av. Dom Orlando (direção Cristo Rei em Várzea Grande e Ponte Nova direção Cuiabá) com a Av. Miguel Sutil (anel viário do município de Cuiabá).

Avenida Dom Orlando Chaves é a segunda mais importante de Várzea Grande na hierarquia viária, por conta da ligação com o Aeroporto Internacional à Ponte Sérgio Mota e a Júlio Muller. Neste trecho do Eixo 1 do VLT, foram previstas a implantação dos trilhos do modal de pelo menos $6 \mathrm{~km}$ do Aeroporto Internacional até a Ponte Júlio Muller que dá acesso ao centro comercial e histórico de Cuiabá e continuidade ao traçado do eixo 1 do VLT. Em Cuiabá, o VLT passaria pelas avenidas: Quinze de Novembro, Tenente Coronel Duarte - Prainha, Historiador Rubens de Mendonça - Av. do CPA com extensão de $9 \mathrm{~km}$ da Ponte Júlio Muller até o Centro Político Administrativo, ao Morada da Serra e a Área de Expansão Urbana Norte, totalizando o eixo um com $15 \mathrm{~km}$ de extensão.

O Eixo dois foi projetado nos bairros da regional sul-leste de Cuiabá, tendo o sentido Sul Centro - Oeste de Cuiabá pelas Avenidas Fernando Corrêa da Costa e Coronel Escolástico. Interseções ao corredor principal do VLT: Av. Tenente Coronel Duarte indo até o Terminal do Coxipó na interseção com Av. Fernando Côrrea da Costa - MT - 040 extensão de 7 km.

O projeto executivo de arborização do Consórcio VLT Cuiabá/Várzea Grande em virtude da paralisação das obras não foi concretizado. Mesmo que a supressão da vegetação nas vias estruturais do traçado tenham sido efetivadas quase integralmente. O projeto de paisagismo não foi executado, permanecendo o memorial botânico proposto pelo Instituto Naturae (INAE), com mais de trinta espécies nativas para arborização, sem qualquer aplicação na realidade urbana das vias.

As alterações na paisagem no decorrer dos anos 2.011, 2.012, 2.014 e 2.015 foram inerentes a 
supressão da cobertura vegetal dos canteiros centrais e das calçadas, impermeabilização do solo e implantação de obras civis de grande porte, tais como viadutos e trincheiras na AID do VLT. Pois este modal foi projetado para passar pelos canteiros centrais das principais vias do Aglomerado Urbano Cuiabá/Várzea Grande. Sendo assim, foram liberadas a retirada da cobertura vegetal e de outros obstáculos nos eixos do projeto do VLT.

A abertura dos canteiros centrais com vegetação para serem transformados temporariamente em canteiros de obras ocorreram com o processo identificado como de acentuado desmatamento urbano, principalmente, na área sobre a influência direta das obras de implantação do VLT (LATORRACA NETTO, 2013), expandindo-se para as regiões da cidade próximas ao raio de atuação das obras de mobilidade urbana.

Há uma forte tendência para a impermeabilização do solo nas novas centralidades que possivelmente surgirão com a operação do sistema de transporte sobre trilhos. Para implantação do traçado, aproximadamente 1.330 indivíduos arbóreos seriam retirados da área, no entanto, com o impasse e atrasos para a conclusão da obra, esse número não foi alcançado, mas mesmo assim, permaneceu o processo intenso de transformação da paisagem, implicando para o aprofundamento das problemáticas, sobretudo, dos componentes ambientais diretamente ligados ao uso e ocupação do solo urbano com destaque para a cobertura vegetal.

O mosaico de Figuras 1, 2 e 3 a seguir, têm os mesmos ângulos em tempos e estações do ano diferentes, porém expressam nitidamente alguns impactos na paisagem do Eixo um, em duas centralidades diferentes, que apresentam uma dinâmica territorial interna crescente do usoocupação do solo.

Figura 2. Paisagem no Eixo 1 da Avenida Hist. Rubens de Mendonça na Regional Norte de Cuiabá Futura Estação do VLT Senegal e Bosque da Saúde entre os anos (2011, 2013, 2014, 2015).
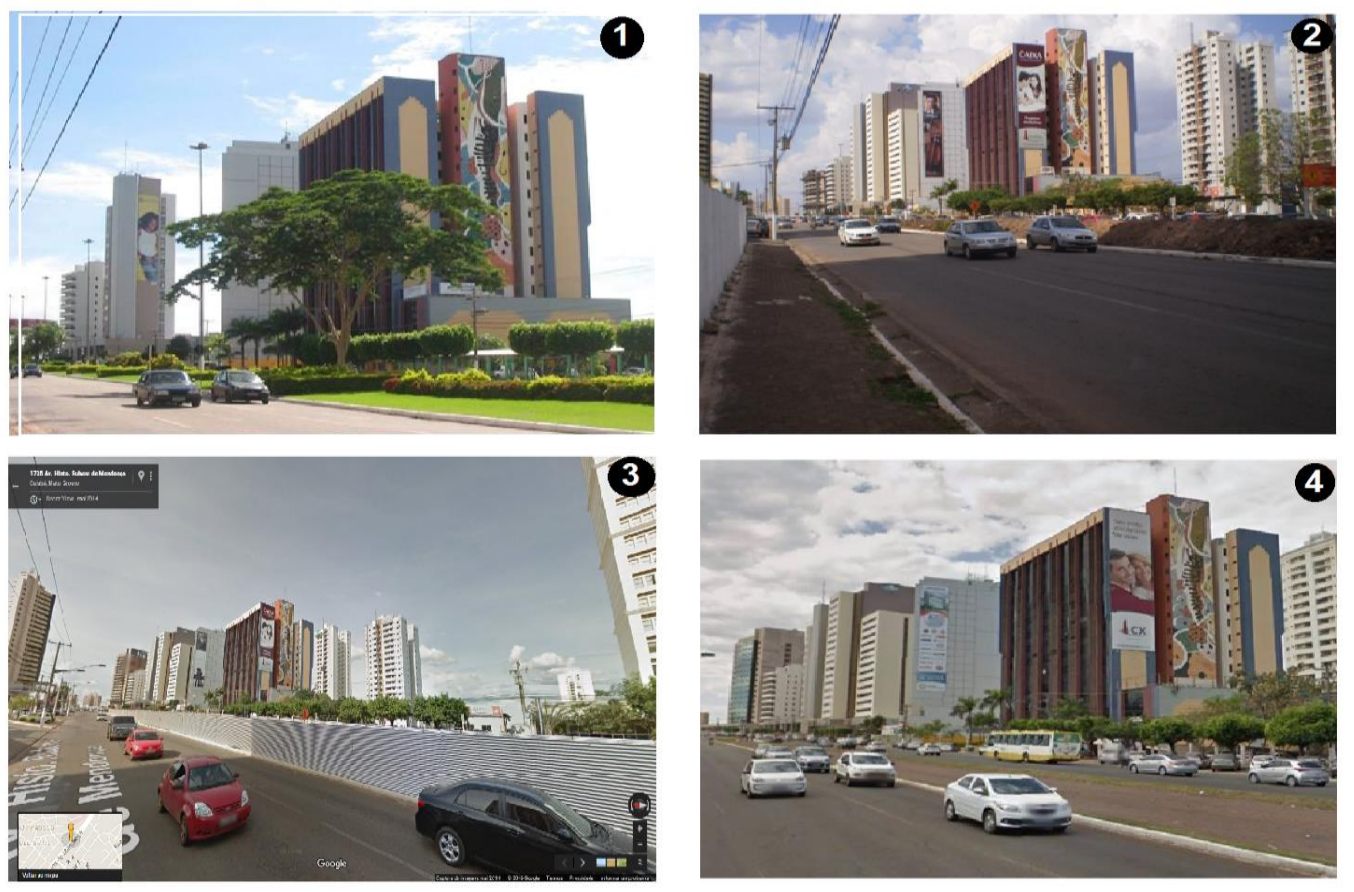

${ }^{1}$ Ano: 2011 - Trecho da Avenida Historiador Rubens de Mendonça - Eixo 1 VLT. Foto: Ademar Poppi, 2011. ${ }^{2}$ Ano: 2013 - Trecho da Avenida Historiador Rubens de Mendonça - Eixo 1 VLT. Foto: Latorraca Netto, 2012. ${ }^{3}$ Ano: 2014 - Trecho da Avenida Historiador Rubens de Mendonça - Eixo 1 VLT. Foto: Google Street View, 2014. ${ }^{4}$ Ano: 2015 - Trecho da Avenida Historiador Rubens de Mendonça - Eixo 1 VLT. Foto: Latorraca Netto, 2015. 
O mosaico de Figuras 2 mostra um dos trajetos mais importantes do projeto VLT, no que se referem às atividades econômicas da Avenida Historiador Rubens de Mendonça - Av. do CPA, foi possível observar o desenvolvimento caótico da cidade, por uma análise referenciada na Ecologia da Paisagem, tem gerado inúmeros impactos na estrutura funcional e dinâmica da paisagem, de forma a pressionar cada vez mais as áreas protegidas, a vegetação, os cursos de água, os espaços livres de construção.

O mosaico da Figura 3 apresenta algumas características importantes quanto aos componentes geoambientais e urbanos em um trecho do eixo dois do VLT em Cuiabá. Em destaque, a paisagem urbana modificada no período dos anos 2.009, 2.011, 2.012 e 2.015 em que as obras estavam sendo executadas pelo Consórcio VLT Cuiabál Várzea Grande e a construção e implantação da avenida Parque Barbado, pelo Consórcio Guaxe-Ecomind, na avenida Fernando Côrrea da Costa sob as centralidades da UFMT e do Shopping Três Américas.

Mosaico de Figuras 3. Avenida Fernando Côrrea - Eixo 2 do VLT (2009, 2011, 2012 e 2015).
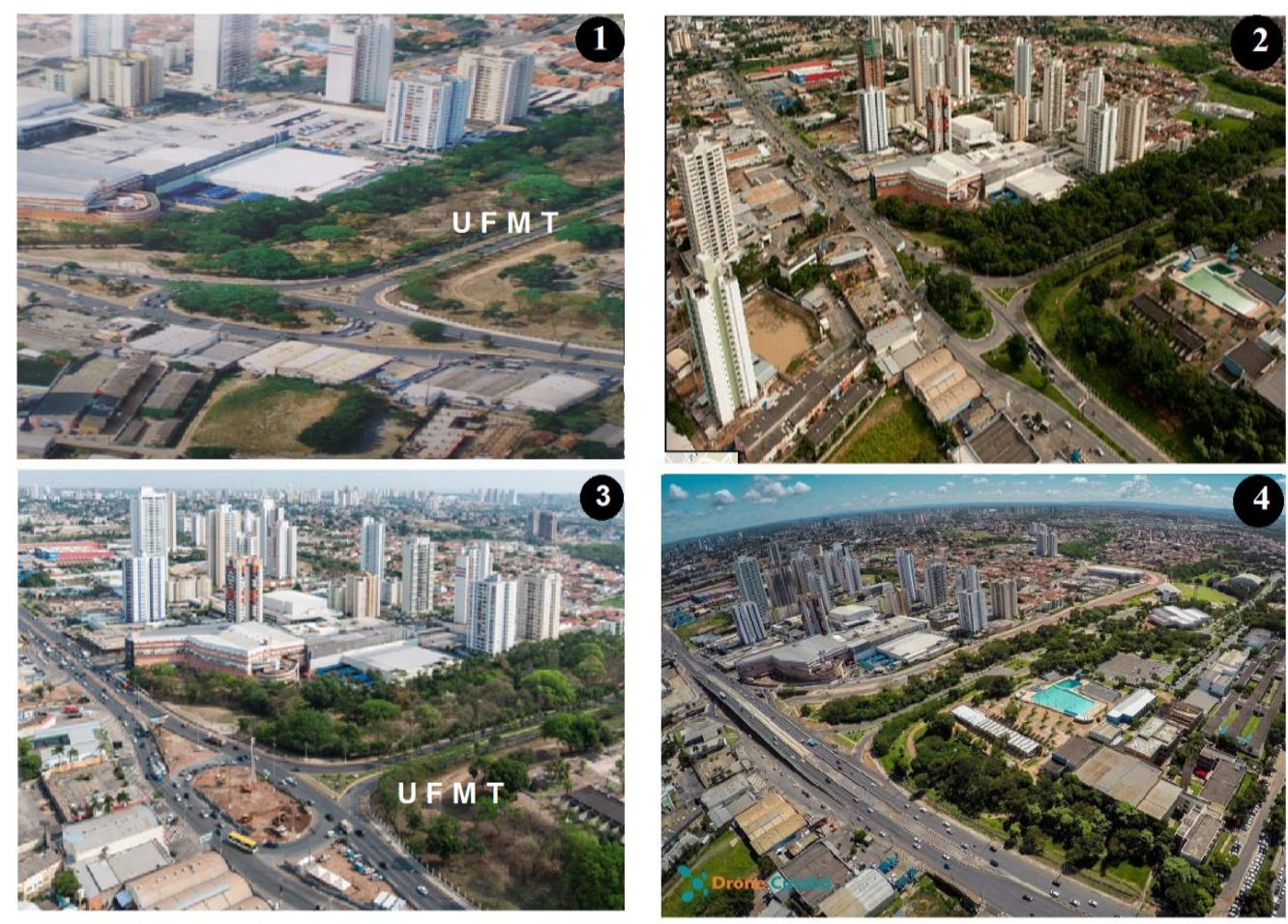

${ }^{1}$ Ano: 2009 - Rotatória na Av. Fernando Côrrea da Costa e entrada principal da UFMT - Eixo 2 do VLT anterior a 2010. Foto: Imobiliária e Construtora São Benedito. ${ }^{2}$ Ano: 2011 - Visão Panorâmica da Av. Fernando Corrêa da Costa, do trevo da rotatória da UFMT que deu lugar ao Viaduto da UFMT finalizado em 2013. Fonte: <Panoramio.com> Fernando Giordani/2011. ${ }^{3}$ Ano: 2012 - Rotatória na Av. Fernando Côrrea da Costa e entrada principal da UFMT - Eixo 2 do VLT. Foto: Secopa, MT/2012. ${ }^{4}$ Ano: 2015 Visão Panorâmica do Viaduto da UFMT construído na Avenida Fernando Corrêa da Costa - Eixo 2 do VLT e do córrego Barbado canalizado em partes e a sua vegetação já quase completamente retirada. Fonte: Drone Cuiabá/2015

A Figura 1 (mosaico 3), do eixo dois do VLT, foi captada em 2.009 e refere-se ao trecho viário em que se instalou o Viaduto da UFMT (denominado Viaduto Jornalista Clóvis Roberto), concluído em 2013. O entroncamento do tráfego de veículos entre a Avenida Fernando Côrrea da Costa com a Avenida Parque Barbado sobre o Córrego Barbado, canalizado, tinha o objetivo 
de garantir viabilidade na da ligação norte-leste ao centro-sul de Cuiabá.

Porém, podemos notar que da Figura 3 à 4 do mosaico 3, houve muitas alterações na cobertura vegetal ripária anteriormente presente na Área de Preservação Permanente (APP), do Córrego Barbado, que deu lugar ao asfalto e ao concreto, permanecendo o curso de água retificado e canalizado, conforme observamos nas figuras do mosaico 3.

As figuras apresentadas expõem alterações que foram identificadas em todo o traçado do VLT, principalmente: a retirada da vegetação arbórea, a intensificação da impermeabilização do solo, o aumento do número e do tempo gasto nos congestionamentos, o aumento de enchentes e alagamentos em pontos onde as obras de drenagem não foram adequadas, mesmo com um montante elevado de recursos que foram gastos. Notam-se através dessas análises iniciais que houveram retrocessos significativos com potenciais interferências na qualidade ambiental e de vida da população, tanto as diretamente atingidas pelas obras de implantação do VLT, como as populações habitantes das regiões periféricas da cidade e, periféricas, não obstante, dos investimentos em mobilidade urbana advindos para a realização dos jogos da Copa do Mundo 2.014 nas cidades.

\section{CONSIDERAÇÕES FINAIS}

As formas e os modos da produção capitalista do espaço têm revelado um modo insustentável de urbanização, a começar pelo caos na mobilidade no sentido amplo e da acessibilidade no sentido do direito à cidade. A acessibilidade não só física, mas também aquela, da dimensão simbólica do acesso aos locais, às centralidades, aos espaços livres/ públicos urbanos e, como analisa Loboda (2013), a todas às condições dos sujeitos e de sua mobilidade na cidade. Nesta afirmação, os objetivos centrais acerca dos investimentos dispensados do Tesouro Nacional e Estadual para a implantação do VLT não foram concluídos em resultados reais na constituição de um desenvolvimento urbano integral.

A questão do desenvolvimento urbano é um tema presente inúmeras vezes como objeto de preocupação central nos 'Planos Estratégicos do Estado', porém, susceptíveis aos interesses políticos, em suas práticas, assumem livremente o plano econômico da indústria da construção civil: empreiteiras, construtoras, imobiliárias, incorporadoras, dentre outros que compõe o acordo de um grande projeto hegemônico de cidade que não considera o conteúdo ecológico para o desenvolvimento urbano.

A densidade populacional (distribuição espacial da população por hectares na AID do VLT) e a cobertura vegetal (impactos da urbanização sobre a vegetação) constituíram elementos necessários para compreender a realidade socioambiental da área de estudo.

A paisagem como uma entidade espacial que envolve todos os componentes geoambientais e urbanos, analisada anteriormente da execução das obras do VLT, são até então, as que mais se transformaram com relação ao intervalo de tempo 2.011, 2.012, 2.013, 2.014 e 2.015, pois, as obras causaram a: remoção da cobertura vegetal quase completa que incidiam adiante do caminho traçado pelo projeto nos canteiros centrais e nas calçadas.

As obras do VLT foram realizadas sem a publicidade ampla de um projeto executivo por parte da empresa contratada, apenas se verificavam a existência de um projeto básico. O reordenamento político - institucional advindo da criação de uma Secretaria de Estado extraordinariamente para administrar as obras da Copa, era operada por uma estrutura composta por agentes políticos econômicos em várias escalas de conexões locais e não - locais, foi implantada na cidade exclusivamente a atender as demandas pelas readequações e reestruturação urbana para a Copa do Mundo 2.014 e, não para ampliar o debate sobre o direito à cidade, nem tampouco sobre os modelos de planejamento em voga no cerne das grandes obras. Permaneceu a expansão massiva dos espaços construídos e da transformação da paisagem. 


\section{NOTAS}

1 O crescimento urbano das duas cidades: Cuiabá e Várzea Grande gerou uma conurbação, criando-se o Aglomerado Urbano Cuiabá - Várzea Grande pela Lei Complementar Estadual n. ${ }^{\circ}$ 028/1993 disposta pela Lei Complementar Estadual n. ${ }^{\circ}$ 83/2001. Porém, com a Lei Complementar n. ${ }^{\circ}$ 359/2009 criou-se a Região Metropolitana do Vale do Rio Cuiabá (RMVRC), tendo por base a Lei Complementar n. ${ }^{\circ}$ 340/2008 ampliando o número de municípios integrantes.

2 CNES: Centre National d'Éstudes Spatiales - Agência Espacial Francesa.

3 Edital no 004/2012/SECOPA Modalidade RDC - Seleção e Contratação de empresa de consultoria especializada para o gerenciamento e supervisão dos Projetos Básicos e Executivos e da realização de todas as obras e instalações, obtenção de Licenças Ambientais, Fornecimento e Montagem de Sistemas e Material Rodante para a Implantação dos Corredores Estruturais de Transporte Coletivo na Região Metropolitana do Vale do Rio Cuiabá - RMVRC, modal Veículo Leve sobre Trilhos - VLT.

4 Ranking de Obras mais caras para a Copa do Mundo no Brasil - $2014<$ http://lista10.org/diversos/as10-obras-mais-caras-para-a-copa-do-mundo-2014/>

5 <olhardireto.com.br> Reportagem do dia 14 de dezembro de 2014. Foto: Rogério Florentino, 2014

\section{REFERENCIAS}

AMORIM, M. C. de C. T. Clima Urbano: Concepções Teóricas, Metodológicas, Aplicações e perspectivas. pp.69-85 Anais do XVI Simpósio Brasileiro de Geografia Física Aplicada: Territórios Brasileiros: dinâmicas, potencialidades e vulnerabilidades. 2015.

BERTRAND, G. Paisagem e Geografia Física Global, Esboço Metodológico. Caderno de Ciências da Terra No. 13. p.01-27. São Paulo: FFLCH/USP, 1972.

BROUDEHOUX, A. Construção da imagem urbana orientada por grandes eventos: Potemkinismo, a mídia e a periferia. pp.19-34. In: SÀNCHEZ, F.; BIENENSTEIN, G.; OLIVEIRA, F. L. de.; NOVAIS, P. (orgs). A Copa do Mundo e as cidades: políticas, projetos e resistências. Niterói, RJ: Editora da UFF, 2014.

CASSETTI, V. A Natureza do Espaço Geográfico. 145-164p. 2002. In: MENDONÇA, F. KOZEL, S. Elementos da Epistemologia da Geografia Contemporânea. Curitiba: Editora da UFPR, 2002.

VILARINHO NETO, C. S. A Metropolização Regional: Formação e Consolidação da rede urbana do estado de Mato Grosso. Cuiabá: EdUFMT, 2009.

CUIABÁ, Prefeitura Municipal de Cuiabá - Instituto de Planejamento e Desenvolvimento Urbano IPDU. Diretoria de Pesquisa e Informação - DPI. Perfil Socioeconômico de Cuiabá - Volume IV. Cuiabá: 2010.

CUIABÁ, Prefeitura Municipal de Cuiabá/ Uso, Ocupação e Urbanização do Solo - Legislação. SMDU Secretaria Municipal de Desenvolvimento Urbano. Cuiabá: 2011.

CUIABÁ, Prefeitura Municipal de Cuiabá: Hierarquização Viária <http://www.cuiaba.mt.gov.br/upload/arquivo/hierarquizacao_viaria_perfil_iv.pd>

GUARIM, V. L. M. dos S.; VILANOVA, S. R. F. Parques Urbanos de Cuiabá, Mato Grosso: Mãe Bonifácia e Massairo Okamura. Cuiabá-MT: Entrelinhas e EdUFMT, 2008.

LATORRACA NETTO, A. Vegetação Urbana e Qualidade Ambiental: Estudo de caso do Eixo 2 Do VLT em Cuiabá-MT. Trabalho de Conclusão de Curso em Geografia. Universidade Federal de Mato Grosso - ICHS: Cuiabá-MT, 2013.

LATORRACA NETTO, A. Impactos Socioambientais e Qualidade Ambiental Urbana: o caso do Veículo Leve sobre Trilhos em Cuiabá, Mato Grosso. Dissertação (Mestrado em Geografia). Universidade Federal de Mato Grosso/Programa de Pós-Graduação em Geografia. 2016. 
LOBODA, C. R. Uma Análise das formas, dos usos e da Apropriação dos Espaços Públicos na cidade de Guarapuava - PR. In: BOVO, M. C.; TOWS, R. L.; COSTA, F. R.(Org). Estudos Urbanos em Perspectivas: reflexões, escalas e desafios. Campo Mourão: FECILCAM, 2013.

MARTINS, C. Q. Efeitos do uso do solo no aquecimento do ar em ambientes urbanos em Cuiabá-MT. Dissertação (Mestrado em Geografia). Universidade Federal de Mato Grosso - ICHS: Cuiabá, 2005.

MENDONÇA, F. Sistema Socioambiental Urbano: Uma abordagem dos problemas socioambientais da cidade. (p.185-208). In: MENDONÇA, F. (org.) Impactos Socioambientais Urbanos. Curitiba: Editora UFPR. 2009.

ROMANCINI, S. R. A avenida historiador Rubens de Mendonça: a redefinição da centralidade urbana em Cuiabá. Revista Mato-grossense de geografia. N. 05/06, p.106-131. Cuiabá, UFMT, 2000/2001.

ROMANCINI, S. R. Reestruturação urbana e novos territórios em Cuiabá. In ROMANCINI, S. R. (Org). Novas Territorialidades em Mato Grosso. 274p. EdUFMT, 2009.

SÀnCHEZ, F.; BIENENSTEIN, G.; OLIVEIRA, F. L.; NOVAIS, P. (orgs). A Copa do Mundo e as cidades: políticas, projetos e resistências. Niterói, RJ: Editora da UFF, 2014.

SEPLAN - MATO GROSSO - Secretaria de Planejamento e Coordenação Geral do Estado de Mato Grosso. Base Cartográfica. 2011. Atlas de Mato Grosso: abordagem socioeconômica e ecológica. CAMARGO, L. (org). Governo do Estado de MT. 2011.

SOUZA-HIGA, T. C. C.; MORENO, G. Geografia de Mato Grosso: território, sociedade e ambiente. $2^{\mathrm{a}}$ edição atualizada e ampliada. Cuiabá: Entrelinhas, 2017.

SIQUEIRA, E. M. História de Mato Grosso: da contemporaneidade aos dias atuais. $2^{\text {a }}$ edição atualizada e ampliada. Cuiabá: Entrelinhas Editora, 2017.

TEOBALDO NETO, A.; AMORIM, M. C. de C. T. Ilha de Calor Urbana e desconforto térmico: uma análise episódica em Cuiabá/MT. XVII Simpósio Brasileiro de Geografia Física Aplicada. I Congresso Nacional de Geografia Física: Os desafios da Geografia Física nas fronteiras do conhecimento. DOI: 10,20396/sbgfa.v1i2017,2059. ISBN: 978-85-85369-16-3. 2017.

VAINER, C. Como serão nossas cidades após a Copa e as Olimpíadas? p. 71 - 78. 2014. In: JENNINGS, A.; ROLNIK, R.; LASSANCE, A. [et.all.]. Brasil em Jogo: o que fica da Copa e das Olimpíadas?. $1^{\text {a }}$ Edição. São Paulo: Boitempo: Carta Maior, 2014.

ZAMPARONI, C.A.G.P.; ROSSETTO, C. O. Diagnóstico Socioeconômico da Implantação da Avenida Parque do Barbado- Cuiabá/MT (relatório). (Volume I e II). Coordenação _ Cuiabá, MT: Universidade Federal de Mato Grosso; Secretaria da Copa. Governo do Estado de Mato Grosso. 2012.

ZAMPARONI, C.A.G.P. Riscos e Desastres Naturais em Ambiente Urbano: O Exemplo de Cuiabá/MT. Revista Brasileira de Climatologia. Ano 8 - Volume: 10. Jan/Jun, 2012.

ZAMPARONI, C.A.G.P. Análise de Mapeamentos de Áreas de Riscos Hidrológicos em Cuiabá/MT/Brasil. III Congresso Internacional, VIII Encontro Nacional de Riscos. Capítulo 3.2: Riscos Climáticos e Hidrológicos. 2014.

\section{DOCUMENTOS:}

CGE-MT. Relatório de Auditoria n019/2015. Contratos n037/2012/SECOPA e nº 001/2013/SECOPA Implantação do VLT. Ordem de Serviço: nº 045/2015/CGE/MT. Interessado Estado de Mato Grosso. Controladoria Geral do Estado de Mato Grosso - CGE. 2015.

Lei n. 6.938/1981 - Avaliação de Impacto Ambiental (AIA). Instituto Brasileiro do Meio Ambiente e dos $\begin{array}{llllll}\text { Recursos } & \text { Naturais } & \text { Renováveis } & - & \text { IBAMA. } & 2016\end{array}$ https://www.ibama.gov.br/phocadownload/noticias/noticias2016/resumo_executivo.pdf> Acesso em 06/07/2019.

MATO GROSSO, AGECOPA-MT. Relatório Final do Plano de Mobilidade Urbana da Região Metropolitana do Vale do Rio Cuiabá -RMVRC. Cuiabá: Governo do Estado de Mato Grosso. Agência Estadual de Execução dos Projetos da Copa do Mundo FIFA - 2014 - AGECOPA - MT; Oficina de 
Engenheiros Consultores Associados Ltda.; Associação de Criadores de Mato Grosso - ACRIMAT. 334p. Relatório Final - Dez.2010.

IBGE, Instituto Brasileiro de Geografia e Estatística. Censo Demográfico, 2010.

IBGE, Instituto Brasileiro de Geografia e Estatística. Plataforma no website do IBGE: Cidades@. Acesso em: < http://cidades.ibge.gov.br/>

INAE, CONSÓRCIO VLT CUIABÁ - VÁRZEA GRANDE. Estudo e Relatório e Impacto Ambiental do VLT na Região Metropolitana do Vale do Rio Cuiabá (Cuiabá e Várzea Grande). Instituto Naturae Consórcio VLT/Governo do Estado de Mato Grosso. Cuiabá/MT: 2012. Disponível em: <www.sema.mt.gov.br/EIARIMAVLT> Acessado em: 15/12/2012.

Parecer Técnico n. 66.513/SUIMIS - 2012 - Viabilidade Ambiental do VLT. Conselho Estadual do Meio Ambiente - CONSEMA - MT. 2012.

SECOPA - MT, Anteprojeto do VLT. Secretaria Extraordinária da Copa do Mundo FIFA 2014. Justificativa Técnica do Modal de Transporte VLT. Características Gerais do Transporte Urbano em Cuiabá e Várzea Grande e Necessidade do Empreendimento, Estudos Preliminares que embasaram a concepção adotada no Anteprojeto. Especificações e Diretrizes Para a Contratação dos Projetos, das Obras Civis, Dos Sistemas, Do Material Rodante e Das Licenças Ambientais. SECOPA-MT em 17/10/2011). Governo do Estado de Mato Grosso. SECOPA - MT. Partes: I, II, III, IV - 2011. 